\title{
Mending Milankovitch's theory: obliquity amplification by surface feedbacks
}

\author{
C. R. Tabor ${ }^{1}$, C. J. Poulsen ${ }^{1}$, and D. Pollard ${ }^{2}$ \\ ${ }^{1}$ Department of Earth and Environmental Sciences, University of Michigan, Ann Arbor, MI, USA \\ ${ }^{2}$ Earth and Environmental Systems Institute, Pennsylvania State University, State College, PA, USA
}

Correspondence to: C. R. Tabor (crtabor@umich.edu)

Received: 30 May 2013 - Published in Clim. Past Discuss.: 5 July 2013

Revised: 26 November 2013 - Accepted: 28 November 2013 - Published: 10 January 2014

\begin{abstract}
Milankovitch's theory states that orbitally induced changes in high-latitude summer insolation dictate the waxing and waning of ice sheets. Accordingly, precession should dominate the ice-volume response because it most strongly modulates summer insolation. However, early Pleistocene (2.588-0.781 Ma) ice-volume proxy records vary almost exclusively at the frequency of the obliquity cycle. To explore this paradox, we use an Earth system model coupled with a dynamic ice sheet to separate the climate responses to idealized transient orbits of obliquity and precession that maximize insolation changes. Our results show that positive surface albedo feedbacks between high-latitude annual-mean insolation, ocean heat flux and sea-ice coverage, and boreal forest/tundra exchange enhance the ice-volume response to obliquity forcing relative to precession forcing. These surface feedbacks, in combination with modulation of the precession cycle power by eccentricity, help explain the dominantly $41 \mathrm{kyr}$ cycles in global ice volume of the early Pleistocene.
\end{abstract}

\section{Introduction}

Paleoclimate proxy records often display variations on timescales of $10^{4}-10^{6} \mathrm{yr}$. These climate variations, known as Milankovitch cycles, are quasi-cyclic. They are attributed to the direct and combined effects of changes in Earth's degree of axial tilt (obliquity), direction of axial tilt (precession), and circularity of orbit (eccentricity) (Hays et al., 1976). Milankovitch cycles are thought to be responsible for the growth and retreat of the large Northern Hemisphere (NH) ice sheets that characterize the Pleistocene through the influ- ence of Earth's three orbital/rotational parameters on highlatitude summer insolation. According to Milankovitch's theory, times of high (low) summer insolation produce high (low) rates of summer melting, leading to $\mathrm{NH}$ ice-sheet retreat (growth). This theory is the most widely accepted explanation for the strong correlation between ice-volume proxy records and orbital variations (Hays et al., 1976).

One of the most intriguing inconsistencies between Milankovitch's theory and proxy records is the lack of a strong precession signal in early Pleistocene $(2.588-0.781 \mathrm{Ma})$ icevolume proxies (i.e., benthic $\delta^{18} \mathrm{O}$ from sediment cores), despite the fact that precession accounts for most of the variability in high-latitude summer insolation (Raymo and Nisancioglu, 2003). While the orbital influences of precession/eccentricity can produce a high-latitude $\left(60-75^{\circ} \mathrm{N}\right)$ May, June, July (MJJ) average insolation amplitude that is more than 2.5 times that of obliquity for the cycle extremes of the Pleistocene, the power spectra of the early Pleistocene $\delta^{18} \mathrm{O}$ sediment records show almost no variability at the precession cycle frequency ( $\sim 21 \mathrm{kyr})$. Instead, the bulk of the signal strength appears at the obliquity cycle frequency ( $\sim 41 \mathrm{kyr}$ ) (Lisiecki and Raymo, 2005).

This apparent failure of Milankovitch's theory has led to new hypotheses for how orbital cycles influence ice volume. The recognition that obliquity has a larger influence on the summer half-year meridional insolation gradient, defined as the $25-70^{\circ} \mathrm{N}$ insolation difference averaged over the period between vernal and autumnal equinoxes, than precession has led to the suggestion that variations in gradientdriven northward moisture fluxes enhance ice-sheet sensitivity (Raymo and Nisancioglu, 2003). Alternatively, it has been proposed that changes in the integrated summer energy, the 
total insolation received over the summer half-year period, may drive changes in ice volume (Huybers, 2006). Though precession has a substantial influence on summer insolation strength, because summer insolation amplitude and summer duration are anti-correlated, the changes in integrated summer energy resulting from variations in precession are smaller than the changes in integrated summer energy resulting from variations in obliquity. Finally, it has been suggested that precessional variations in marine $\delta^{18} \mathrm{O}$ records are damped because precession insolation forcing is out-ofphase between hemispheres, potentially causing simultaneous (and partially offsetting) ice-sheet growth and retreat (Raymo et al., 2006; Lee and Poulsen, 2009). Despite these numerous hypotheses, there is no strong consensus as to the cause of the early Pleistocene $\delta^{18} \mathrm{O}$ signal.

Here we employ an Earth system model asynchronously coupled with a thermo-mechanical ice sheet to better understand the differences in climate response to changes in precession and obliquity. We examine the high-latitude climate response to insolation forcing through a sensitivity analysis in which we separate the system responses to obliquity and precession. Our results demonstrate that internal climate feedbacks not considered in Milankovitch's theory help explain the relatively strong obliquity signal observed in the early Pleistocene $\delta^{18} \mathrm{O}$ sediment records.

\section{Methods}

In this study, we use an Earth system model consisting of the GENESIS (Global ENvironmental and Ecological Simulation of Interactive Systems) 3.0 atmospheric global climate model (AGCM) and land-surface model with a slab ocean coupled to a thermo-mechanical sea-ice model (Pollard and Thompson, 1997), the Pennsylvania State University ice-sheet model (Pollard and DeConto, 2012), and the BIOME4 vegetation model (Kaplan et al., 2003). To gain a better understanding of the climate feedbacks and ice dynamics associated with changes in orbital configuration, we design two sets of transient orbit experiments, one without an ice-sheet model (climate-only) and one with an ice-sheet model (climate-ice sheet). For each set of experiments, we run two transient orbital configurations in which either precession or obliquity systematically varies through a full orbital cycle (Table 1) with ranges representing extremes of the Pleistocene (Berger and Loutre, 1991). In our experiments, obliquity and precession cycles are 40 and $20 \mathrm{kyr}$ respectfully, slightly less than the known durations of 41 and $21 \mathrm{kyr}$, for computational efficiency and ease of comparison (DeConto and Pollard, 2003; Horton and Poulsen, 2009). The ice-sheet model is run over a domain consisting of Greenland and North America at latitudes greater than $40^{\circ}$ N. Since our focus is the role of orbital configuration, greenhouse gas concentrations (GHG) are fixed with values representing averages of the last $400 \mathrm{kyr}$ (Petit et
Table 1. Orbital configurations.

\begin{tabular}{llll}
\hline Experiment & Obliquity & Precession & Eccentricity \\
\hline OBL & $22.079-24.538^{\circ}$ & NA & 0 \\
PRE & $23.3085^{\circ}$ & $0-360^{\circ}$ & 0.056596 \\
\hline
\end{tabular}

al., 1999; Bender, 2002) $\left(\mathrm{CO}_{2}=230 \mathrm{ppmv}, \mathrm{CH}_{4}=520 \mathrm{ppbv}\right.$, $\left.\mathrm{N}_{2} \mathrm{O}=250 \mathrm{ppbv}\right)$. All simulations use modern continental arrangement and start with modern ice-sheet extents. Resolutions for the AGCM, land surface, and ice-sheet models are $\mathrm{T} 31\left(\sim 3.75^{\circ} \times 3.75^{\circ}\right), 2^{\circ} \times 2^{\circ}$, and $0.5^{\circ} \times 0.25^{\circ}$, respectively. We decrease high Alaskan elevations in our simulations to prevent excessive ice build-up caused by the inability of the AGCM to capture valley ablation in Alaska (Marshall and Clarke, 1999). For these experiments, no floating ice or grounding-line advance into water is allowed in the ice-sheet model. Sea level is lowered by $275 \mathrm{~m}$ relative to modern to allow ice-sheet growth over the Hudson Bay and continental shelf. We find $\sim 275 \mathrm{~m}$ to be the smallest amount of sea level lowering required to prevent flooding of the Hudson Bay when considering isostatic subsidence. The sea level lowering of $275 \mathrm{~m}$ has little influence elsewhere in the model because this is a terrestrial ice model with no explicit marine physics.

Because response times of the atmosphere and ice sheets differ by several orders of magnitude, we apply an asynchronous technique to couple the AGCM and the ice-sheet model (Birchfield et al., 1981). This process involves running the AGCM for short durations of $20 \mathrm{yr}$, passing AGCM outputs to the ice-sheet model, running the ice-sheet model for longer durations of $2.5 \mathrm{kyr}$, and updating the AGCM with new topography and land-surface type. We use an average of the final $10 \mathrm{yr}$ of AGCM outputs to force the ice-sheet model. Due to the continuous nature of the orbital changes and the rapid response time of the slab ocean, $10 \mathrm{yr}$ of spin-up prior to the averaging period is sufficient to produce near equilibrium climate states. Herrington and Poulsen (2011) show that ice-sheet volume is sensitive to the asynchronous coupling period due to ice albedo and atmospheric circulation feedbacks. Here the model produces fairly continuous ice-volume and area responses to the transient orbital forcings, which suggests our coupling time is sufficiently small to capture the majority of the transient climate signal. In the ice-sheet model, we implement an insolation/temperature melt (ITM) scheme (van den Berg et al., 2008) calculated using AGCM outputs instead of the default positive degree-day melt (PDD) scheme (Pollard and DeConto, 2012). Robinson et al. (2010) find that the ITM approach produces greater and more realistic ice-sheet sensitivity in transient climate experiments than the PDD approach, making the ITM scheme preferable for paleoclimate simulations.

We run all ice-sheet experiments for $160 \mathrm{kyr}$ model years, representing 4 cycles of obliquity and 8 cycles of precession. 
The first $40 \mathrm{kyr}$ model years are not considered in our analysis since the ice sheets are still equilibrating during that time. Subsequent cycles are averaged to simplify the results. Because orbits with high eccentricity and transient precession cause significant changes in seasonal duration, we convert monthly AGCM outputs from a Gregorian calendar to an angular calendar using the methods detailed in Pollard and Reusch (2002). All monthly and seasonal analyses use the converted angular calendar outputs. For example, here June refers to the angular month most temporally similar to June in the Gregorian calendar. Furthermore, for our results we define high-latitude insolation as the shortwave radiation received at the top of the atmosphere between 60 and $75^{\circ} \mathrm{N}$. Summer insolation is the average insolation of the angular calendar months May, June, and July. While our results focus mainly on the high latitudes of North America because it is encompassed by the ice-sheet domain, the same general climate responses also occur in the high latitudes of Europe.

\section{Results}

\subsection{Climate-only experiments}

Our initial analysis examines the climate response to transient cycles of obliquity and precession in the absence of dynamic ice sheets. Model results show that differences in the ocean and vegetation feedbacks to the cycles of obliquity and precession produce greater climate sensitivity to insolation forcing from obliquity (described below). This climate sensitivity difference is due in part to the influence of obliquity-controlled variations in annual-mean insolation on the high-latitude ocean. The amount of absorbed insolation by the high-latitude ocean is mainly controlled by the amount of surface incident insolation and sea-ice cover. Because the obliquity cycle generates variations in annual-mean insolation, the high-latitude oceans absorb a greater range of insolation annually from obliquity than precession (Fig. 1a).

Changes in the amount of ocean-absorbed insolation modify the timing of sea-ice growth and retreat (Fig. 1a). Sea-ice coverage produces a positive feedback with oceanabsorbed insolation because of the albedo difference between ocean and ice. The annual-mean insolation signal of obliquity causes the change in ocean-absorbed insolation due to obliquity to be greater than those due to precession, resulting in a larger sea-ice response. Direct insolation also accounts for some of the sea-ice melting. However, the strong correlation between annual-absorbed insolation and seasonal sea-ice coverage suggests the direct insolation signal is of less importance. The contrast in sea-ice coverage is particularly apparent during spring and fall (not shown). For example, total April sea-ice area varies by $\sim 2065900 \mathrm{~km}^{2}$ through an obliquity cycle but only $\sim 1340300 \mathrm{~km}^{2}$ through a precession cycle, a difference of $\sim 43 \%$. Interestingly, the sea-ice difference does not lead to a large cloud albedo re- sponse. In April, when the difference in sea-ice coverage is largest, the variation in high-latitude cloud albedo over the ocean is only 0.013 for obliquity and precession.

Although smaller than obliquity, precession does have an effect on annual-mean high-latitude ocean-absorbed insolation and sea-ice coverage, despite no annual-mean insolation forcing, due to changes in the timing of seasonal insolation and interactions with sea-ice coverage. Because sea-ice coverage is smallest in the summer, when summer insolation is relatively high the lower albedo of the open-ocean allows it to absorb more of the surface incident insolation, leading to an increase in the amount of annual-mean ocean-absorbed insolation even if there is no change in annual-mean insolation forcing. The summer insolation amplitude changes from obliquity also have some effect on the amount of annualmean ocean-absorbed insolation, but it is smaller than precession, and smaller still than the effect of annual-mean insolation forcing from obliquity on ocean-absorbed insolation, so it is of secondary importance in the transient obliquity experiments.

In combination, the effects of surface incident insolation and sea-ice feedbacks produce an annual-mean high-latitude ocean absorbed insolation amplitude of $\sim 12 \mathrm{Wm}^{-2}$ from obliquity forcing but only $\sim 6 \mathrm{Wm}^{-2}$ from precession forcing (Fig. 1a). The ocean acts as a seasonal energy integrator, which allows it to store and reemit the absorbed insolation as heat throughout the year. During times of maximum (minimum) high-latitude summer insolation, the highlatitude ocean absorbs and releases to the atmosphere a larger (smaller) amount of heat for obliquity than precession. The difference in high-latitude ocean-atmosphere heat flux is plotted in Fig. 1b. The greater heat flux response to obliquity relative to precession adds to the direct insolation heating, increasing the seasonal climate sensitivity to the insolation forcing.

The larger influences of obliquity compared to precession on ocean-atmosphere heat flux and sea ice have been found in other modeling studies (e.g., Gallimore and Kutzbach, 1995). Additionally, Eemian sea surface temperature estimates from planktonic foraminifera along a North Atlantic meridional transect correlate well with local changes in mean annual insolation (Cortijo et al., 1999).

Changes in obliquity also produce greater North American high-latitude vegetation responses, mainly between tundra and boreal forest, than precession (Fig. 1c). In BIOME4, annual net primary productivity (NPP) and number of growing degree days (GDD) above $0{ }^{\circ} \mathrm{C}$ determine the threshold between tundra and boreal forest (Kaplan et al., 2003). Due to annual-mean insolation changes, obliquity produces a larger range of annual temperature and sunlight reaching the surface and accordingly, a larger amount of tundra/boreal forest exchange. While the precession cycle causes large average insolation changes on seasonal timescales, its insolation forcing sums to zero on an annual basis, which reduces the annual-mean changes in surface incident insolation 

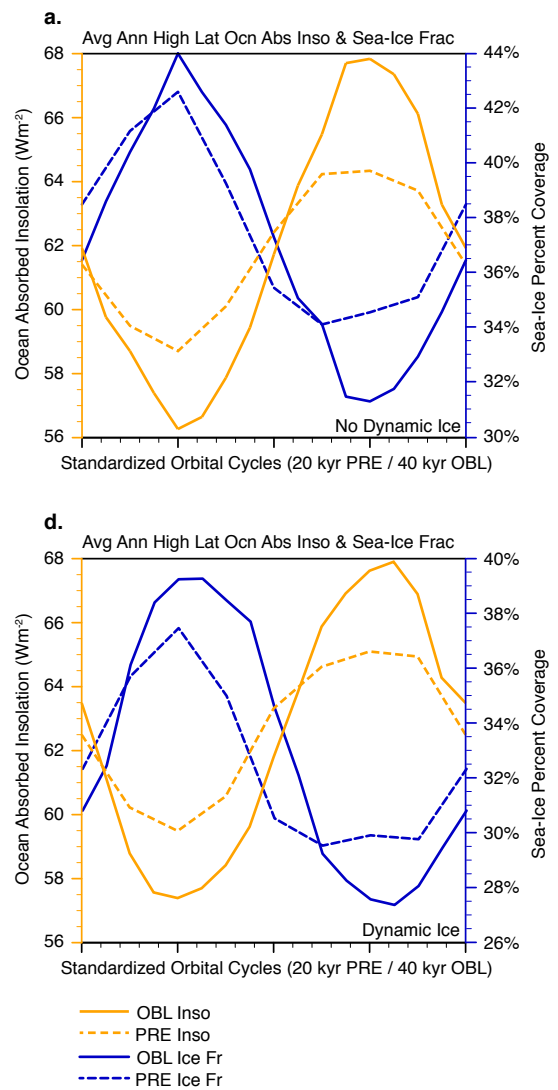
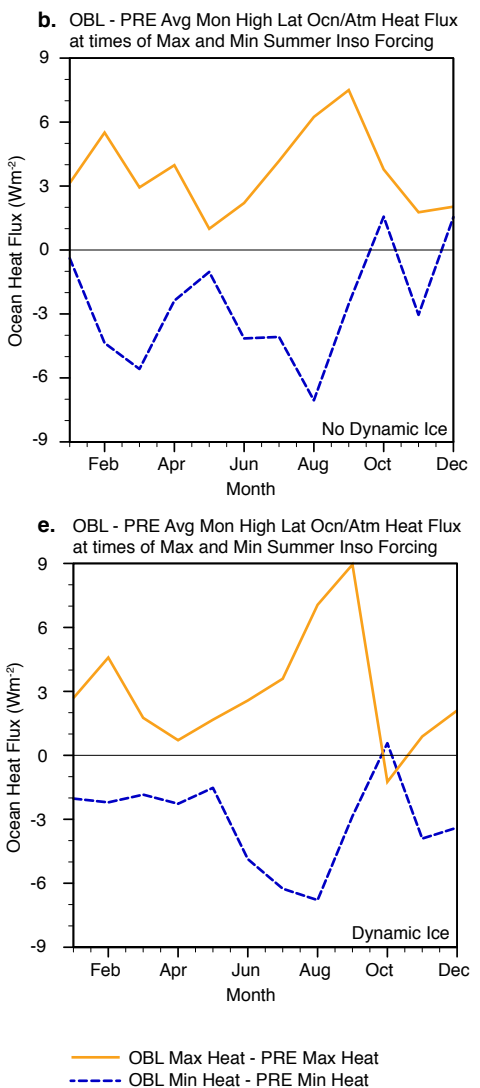

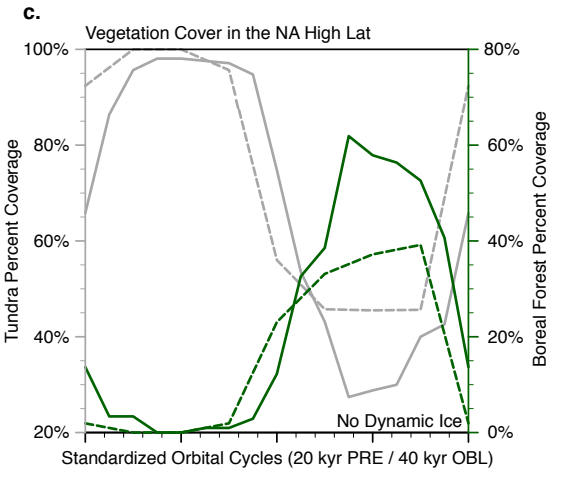

f.

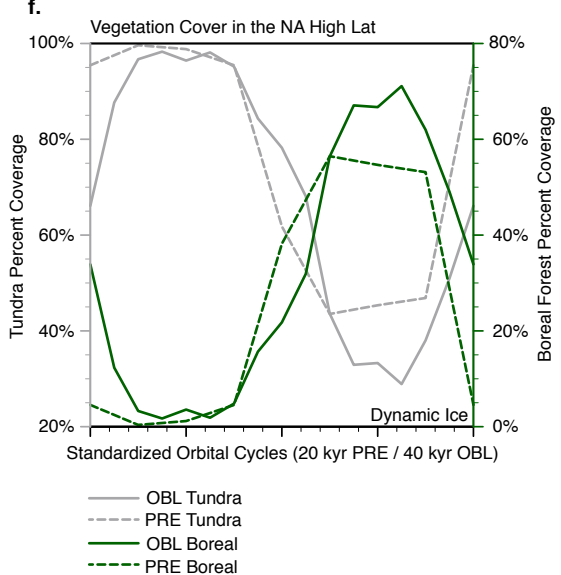

Fig. 1. (a) Annual-mean ocean-absorbed insolation $\left(\mathrm{Wm}^{-2}\right)$ and sea-ice coverage $(\%)$ between 60 and $75^{\circ} \mathrm{N}$ through time for the climateonly experiments. (b) Differences in monthly average sensible + latent heat flux $\left(\mathrm{Wm}^{-2}\right)$ over the ocean between 60 and $75^{\circ} \mathrm{N}$ during the maximum and minimum high-latitude summer insolation forcing from obliquity and precession for the climate-only experiments. (c) Annualmean coverage (\%) of tundra and boreal forest over North America between 60 and $75^{\circ} \mathrm{N}$ through time for the climate-only experiments. (d) Annual-mean ocean-absorbed insolation $\left(\mathrm{Wm}^{-2}\right)$ and sea-ice coverage (\%) between 60 and $75^{\circ} \mathrm{N}$ through time for climate-ice sheet experiments. (e) Differences in monthly average sensible + latent heat flux $\left(\mathrm{Wm}^{-2}\right)$ over the ocean between 60 and $75^{\circ} \mathrm{N}$ during the maximum and minimum high-latitude summer insolation forcing from obliquity and precession for climate-ice sheet experiments. (f) Annual-mean coverage (\%) of tundra and boreal forest over North America between 60 and $75^{\circ} \mathrm{N}$ through time for climate-ice sheet experiments. Cycle lengths were standardized and aligned by peak summer insolation in (a), (c), (d), and (f) to more easily compare the 40 kyr obliquity cycle with the $20 \mathrm{kyr}$ precession cycle. In (a) and (d), the annual-mean insolation (orange lines) and sea-ice coverage (blue lines) amplitudes are greater over the cycle of obliquity (solid lines) than the cycle of precession (dashed lines). The greater annual-mean ocean-absorbed insolation causes the high-latitude ocean to emit a greater range of heat to the atmosphere for the obliquity cycle, which is illustrated in (b) and (e) as the difference (obliquity minus precession) in ocean-atmosphere heat flux for the maximum summer insolation orbit (solid orange) and the minimum summer insolation orbit (dashed blue). High-latitude vegetation change is also more influenced by obliquity than precession. In (c) and (f), obliquity (solid lines) produces a greater transition between tundra (gray lines) and boreal forest (green lines) than precession (dashed lines).

and temperature. As a result, NPP and GDD variations favor obliquity with $22.7 \%$ more land area transitions from tundra to boreal forest in the high latitudes of North America during periods of peak summer insolation from obliquity forcing than precession forcing. The greater boreal forest coverage decreases annual-mean high-latitude North American surface albedo by an additional $0.040(27.6 \%)$ for obliquity compared to precession; the differences are especially large in the winter and spring months (over 0.077 in March) when the tree canopy masks the snow cover.
The lower albedo and greater moisture content of boreal forest compared to tundra causes more near-surface warming year-round. Additionally, like sea-ice changes, the boreal forest/tundra exchange influences the timing of spring warming and fall cooling and amplifies seasonal temperature differences of the orbital extremes. In turn, the timing of snowmelt varies, further modifying surface albedo and temperature responses.

While proxy studies show a correlation between vegetation and orbit (e.g., González-Sampériz et al., 2010), we are not aware of any records directly documenting cycles 
of orbitally driven Arctic taiga-tundra feedback. This feedback has, however, been recognized in modeling studies that looked at snapshot outputs from several orbital configurations (Gallimore and Kutzbach, 1996; Koenig et al., 2011) as well as transient experiments with models of intermediate complexity (Crucifix and Loutre, 2002; Claussen et al., 2006). For instance, Crucifix and Loutre (2002) observe a large high-latitude vegetation (and sea-ice) response to changes in insolation when modeling the transition out of the last interglacial period. In contrast to our results, precession was found to control most of their vegetation feedback. Differences in vegetation transition thresholds and the strength of the insolation forcing might be in part to blame for this discrepancy. Moreover, Horton et al. (2010) find the taigatundra feedback is essential for producing orbitally driven ice-sheet retreat in simulations of late Paleozoic glacial cycles.

The cycles of obliquity and precession both affect seasonal temperatures. However, annual-insolation-enhanced positive feedbacks of ocean heat flux, sea-ice coverage, and vegetation type work synergistically to amplify the temperature sensitivity to changes in the obliquity compared to precession. For all months, obliquity-forced changes in highlatitude insolation produce a larger temperature response than precession (see Supplement, Fig. S1). Arguably the most important temperature sensitivity to insolation forcing for ice-sheet response is during the summer months. The regression in mean, high-latitude North American June, July, August (JJA) surface temperature with MJJ insolation is 1.73 times steeper for obliquity than precession (Fig. 2a, b), resulting in a similar range of summer temperatures despite a large difference in summer insolation amplitude. Even though summer insolation is the dominant factor for determining perennial snow cover through seasonal melting in the high latitudes of North America, annual-mean insolation intensifies the climate response to changes in obliquity.

Studies have proposed that the greater latitudinal summer insolation gradient caused by the obliquity cycle enhances eddy fluxes, which leads to greater Arctic snowfall variability (e.g., Jackson and Broccoli, 2003; Lee and Poulsen, 2008). While the midlatitude eddy fluxes vary as a result of changes in insolation gradient, we find little difference in the $\mathrm{NH}$ high-latitude eddy heat and moisture flux between obliquity and precession (see Supplement, Fig. S2). The small differences in transport that do exist do not reflect the high-latitude temperature sensitivity responses. Therefore, we do not believe transport significantly influences the climate sensitivity differences to orbital forcing we discuss here. Instead, local changes appear to control most of the climate response. Furthermore, moisture flux appears to be of secondary importance, as ablation, not snowfall, dictates the majority of the ice-volume response in our model.

\subsection{Climate-ice sheet experiments}

We ran the same transient orbital configurations of obliquity and precession with the inclusion of an asynchronously coupled thermo-mechanical ice-sheet model. Results show that while high-latitude summer insolation is the main mechanism controlling ice-sheet volume, the ice-sheet rate of change to variations in obliquity and precession are similar (Fig. 3a, b), despite summer insolation changes due to precession being much larger. This is due to ocean heat flux, seaice, and vegetation feedbacks that enhance the temperature response to insolation forcing from obliquity (Figs. 1d-f, 2c). The enhanced temperature range promotes ice growth and retreat. The similar growth and decay rate, combined with the longer cycle duration for obliquity (40 versus $20 \mathrm{kyr}$ ), results in a total ice-volume amplitude that is $42 \%$ larger for obliquity than precession (Fig. 3c).

To evaluate the influence of the different durations of obliquity and precession cycles on ice volume, we ran an additional experiment with a transient obliquity cycle scaled to $20 \mathrm{kyr}$. The percent difference in ice-volume range through a precession cycle is larger by only $22.5 \%$ (Fig. 4b) even though the high-latitude summer insolation range is larger for precession by $87 \%$. The similar ice-volume rate of change and ranges in Fig. 4a and $b$ demonstrate that the annualmean insolation forcing of obliquity and resulting surface feedbacks are strong enough to cancel the nearly 2 times greater MJJ summer insolation forcing of precession. Additionally, the standardized duration experiment shows that the potential lesser damping of the $40 \mathrm{kyr}$ obliquity forcing due to ice-sheet mass inertia and isostasy (vs. $20 \mathrm{kyr}$ for precession) would be insufficient on their own to yield the greater obliquity response in Fig. 3c. Without considering the surface feedbacks to the annual-mean insolation forcing from obliquity, Milankovitch's theory is unable to explain the relative amplitudes of ice-sheet response in our model results.

In all climate-ice sheet experiments, the ice-volume cycles of growth and retreat are fairly symmetric. We note that the $\delta^{18} \mathrm{O}$ signal of the early Pleistocene is also fairly symmetric; only after the mid-Pleistocene transition with the appearance of the $100 \mathrm{kyr}$ cycle does asymmetry become significant. The near-symmetry of the modeled ice-volume cycles is likely in part a response to the idealized nature of our experiments that include a large, fixed value of eccentricity and no greenhouse gas fluctuations. We do not expect the ice-volume responses would maintain the same amount of symmetry if these additional factors were included in the model.

\section{Discussion and conclusion}

The results of this study show that positive surface feedbacks enhance the ice-volume response to the cycles of obliquity relative to precession. Our choice of orbital configurations further highlights the influence of obliquity on the climate 
a.

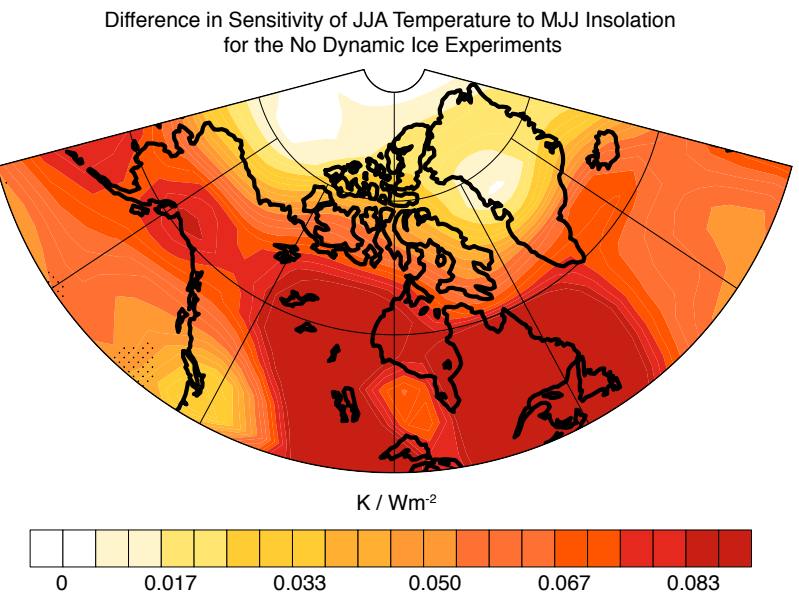

b.

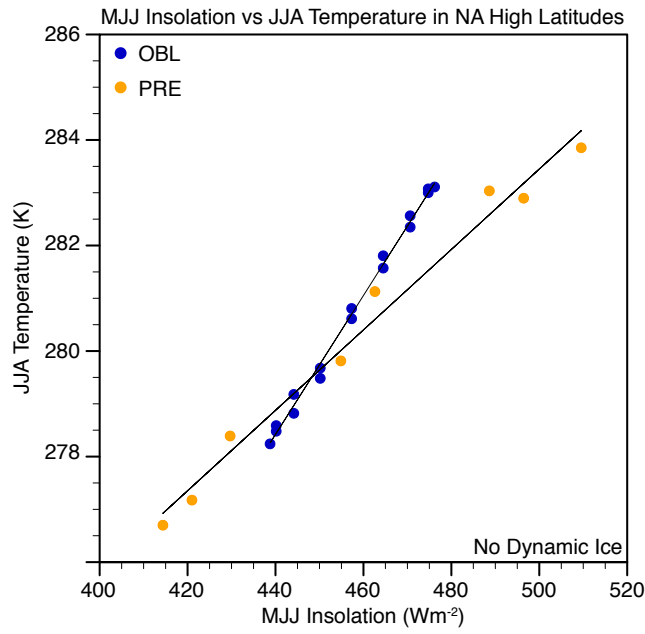

c.

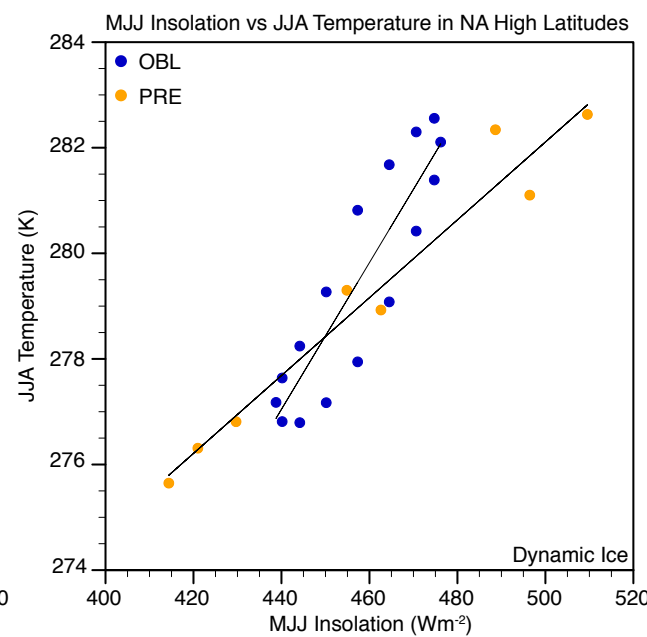

Fig. 2. (a) The regression slope of MJJ insolation against JJA temperature $\left(\mathrm{K}\left(\mathrm{Wm}^{-2}\right)^{-1}\right)$ for obliquity minus precession over northern North America for the climate-only experiments. Stippling represents areas where linear regressions are not significant at the $95 \%$ confidence level. (b) JJA temperature response to MJJ insolation forcing from obliquity and precession averaged over North America between 60 and $75^{\circ} \mathrm{N}$ for climate-only experiments. (c) JJA temperature response to MJJ insolation forcing from obliquity and precession averaged over North America between 60 and $75^{\circ} \mathrm{N}$ for climate-ice sheet experiments. In (b) and (c), each dot represents the AGCM averaged equilibrium output for a given orbital configuration. Here we choose a 1 month delay for the temperature response to incoming insolation because it has the best linear relationship. Using a 2 month delay produces a similar insolation-temperature relationship with obliquity still having much greater temperature sensitivity than precession.

system. Insolation forcing from precession changes significantly between cycles due to power modulation by eccentricity. Here we use the largest eccentricity value of the Pleistocene, producing the maximum precession summer insolation amplitude. A precession cycle with similar summer insolation amplitude to these experiments occurs at most once every $100 \mathrm{kyr}$. Like the precession cycle, the obliquity cycle in these experiments represents the maximum range of the Pleistocene; however, the extreme orbital amplitude of obliquity is a smaller deviation from the average ( $47 \%$ difference) than the extreme orbital amplitude of eccentricity/precession (66\% difference).
In this study, we do not examine the ice-volume response to combined changes in precession, obliquity, and eccentricity. Nevertheless, assuming similar climate feedbacks to our current results, we would expect to find a strong obliquity signal when applying combined orbital forcing as well. The obliquity signal should appear continuously while the precession cycle will only have a significant influence on ice volume when eccentricity is large (every $\sim 100 \mathrm{kyr}$ ), reducing the signal frequency. Combined with the potential for melting offset by Antarctica from precession forcing (Raymo et al., 2006; Lee and Poulsen, 2009), the obliquity dominated $\delta^{18} \mathrm{O}$ record of the early Pleistocene might not be difficult to replicate. However, without invoking a hemispheric 


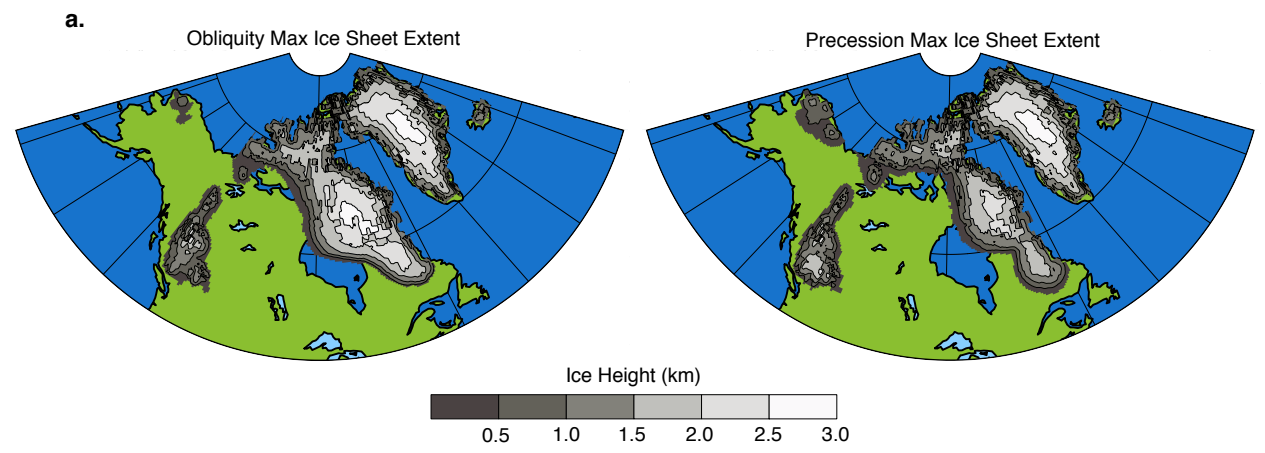

b.

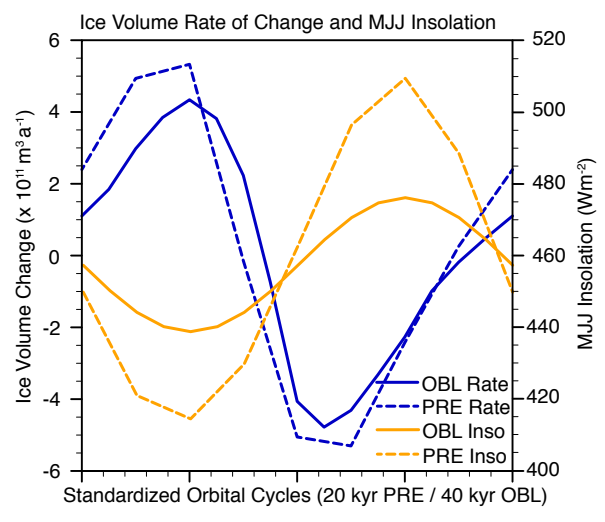

c.

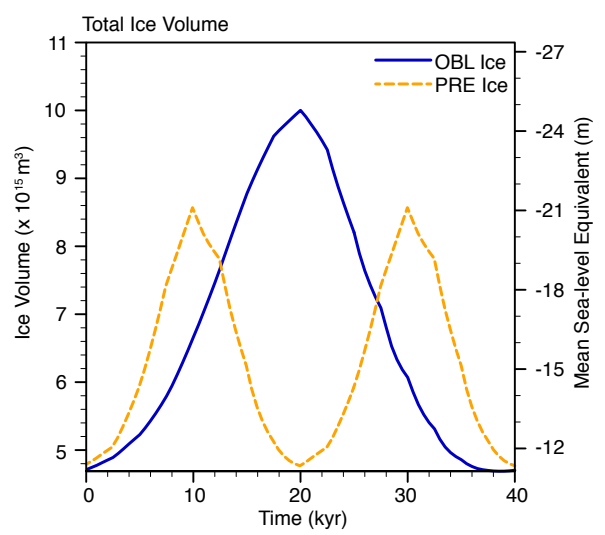

Fig. 3. (a) Maximum ice-sheet extents simulated over the $40 \mathrm{kyr}$ obliquity and $20 \mathrm{kyr}$ precession cycles. (b) Ice-volume rate of change $\left(\mathrm{m}^{3} \mathrm{a}^{-1}\right)$ and $\mathrm{MJJ}$ insolation forcing between 60 and $75^{\circ} \mathrm{N}\left(\mathrm{Wm}^{-2}\right)$ through a $40 \mathrm{kyr}$ cycle of obliquity and a $20 \mathrm{kyr}$ cycle of precession. Cycle lengths were standardized and aligned by peak summer insolation for comparison. (c) Total North American ice volume $\left(\mathrm{m}^{3}\right)$ from obliquity and precession orbital forcing over a $40 \mathrm{kyr}$ period. Mean sea-level equivalent values $(\mathrm{m})$ relative to modern day are also provided.
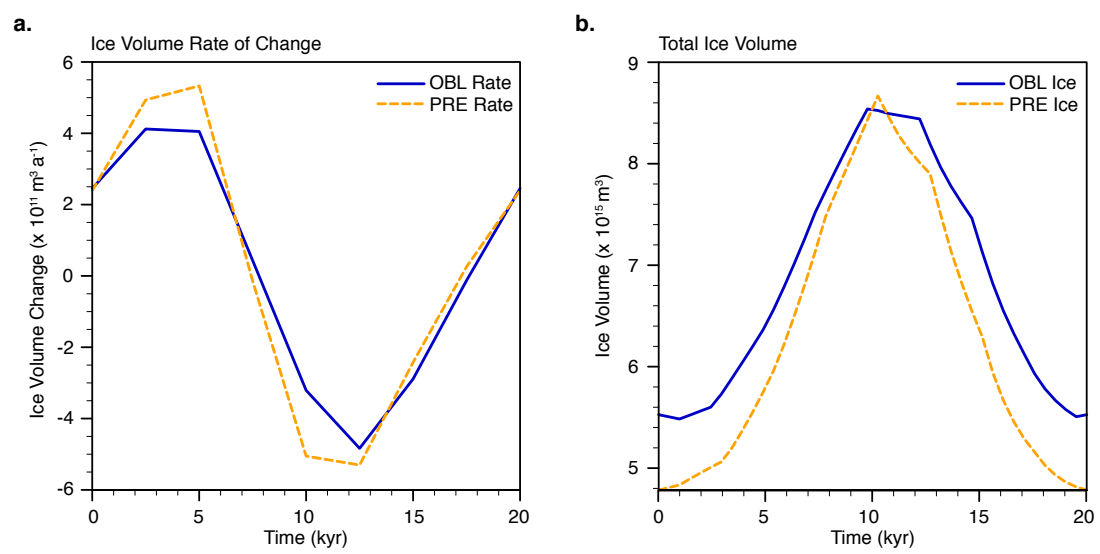

Fig. 4. (a) The ice-volume rate of change $\left(\mathrm{m}^{3} \mathrm{a}^{-1}\right)$ and (b) total North American ice volume $\left(\mathrm{m}^{3}\right)$ for a 20 kyr cycle of obliquity and a $20 \mathrm{kyr}$ cycle of precession.

offset we expect our current model configuration will produce a smaller, yet significant, precession ice-volume signal, which is not found in the early Pleistocene ice-volume proxy records (Lisiecki and Raymo, 2007). Future work will examine the combined interactions between obliquity and precession to help quantify the synergistic interactions.
Our model experiments reveal feedbacks that help explain the early Pleistocene $\delta^{18} \mathrm{O}$ record; yet, the $100 \mathrm{kyr}$ icevolume cycle of the late Pleistocene remains an enigma. It is possible that the amplifying feedbacks associated with annual insolation are lost when considering the much larger ice sheets of the late Pleistocene. Simply covering a much 
greater area of the Arctic with ice could reduce the vegetation feedbacks. Likewise, the cooling effect of a large ice sheet might push the permanent sea-ice extent below latitudes with a large annual-mean insolation signal from obliquity. In this case, the combined insolation forcing of precession and obliquity may be required to trigger ice-sheet retreat. Indeed, statistical analysis of $\delta^{18} \mathrm{O}$ indicates that both obliquity and precession forcings influence ice-sheet retreat during the late Pleistocene (Huybers, 2011).

The goal of this study was to investigate climate sensitivity to orbital configuration rather than simulate specific intervals of ice-volume change. However, it is worth noting that the ice sheets in our experiments are fairly small; over obliquity and precession cycles, the mean sea-level equivalent change is 13.5 and $9.5 \mathrm{~m}$ (Fig. 3c), significantly less than early Pleistocene global sea-level change estimates of 60-80 m (Sosdian and Rosenthal, 2009). Much of this volume change is due to variations in the North American ice sheets, and our simulated ice sheets are much smaller than those at glacial maxima, even for the early Pleistocene (Clark and Pollard, 1998). This discrepancy is likely a combination of factors. First, there is a known warm bias in modernday GENESIS 3 AGCM climate simulations over Northern Canada (Herrington and Poulsen, 2011). Second, our idealized orbits do not capture the strongly reduced NH summer insolation produced by combinations of obliquity, precession, and eccentricity that lead to past glacial maxima. Thirdly, a lack of GHG fluctuations might contribute to the small ice-volume changes in our model (Abe-Ouchi et al., 2007). We plan to address the significance of more realistic climate variability in a future study. Regardless, we believe our results are robust even if the model under predicts the scales of the changes in ice volume.

Our findings support Milankovitch's theory; of all insolation forcings, high-latitude summer insolation forcing has the strongest correlation with the ice-volume rate of change ( $r=$ -0.85 for obliquity and -0.89 for precession) (Fig. $3 b$ ). Yet Milankovitch's theory alone cannot explain the early Pleistocene $\delta^{18} \mathrm{O}$ records or our model results. Surface feedbacks remedy these incongruities. The changes in high-latitude annual-mean insolation resulting from a transient obliquity orbit leads to significant modification in high-latitude ocean heat flux, sea-ice cover, and vegetation type, which work in concert to amplify the annual and seasonal climate sensitivity to changes in insolation. This causes the summer climate sensitivity to changes in insolation from obliquity to become magnified, producing a larger ice-sheet response than expected given the much smaller summer insolation amplitude than precession. These results highlight the significance of annual-mean insolation on the climate and help explain the strength of the obliquity signal found in $\delta^{18} \mathrm{O}$ proxies, particularly before the mid-Pleistocene transition. We demonstrate the amplification of surface feedbacks by obliquity with and without dynamic ice sheets and in a duration-standardized experiment. Our results offer a new explanation of the me- chanisms related to the early Pleistocene Milankovitch theory paradox and emphasize the importance of using complex models when investigating long-term changes in climate.

\section{Caveats}

The long runtime required for our transient orbital experiments makes use of a dynamic ocean unfeasible. Instead, we apply a $50 \mathrm{~m}$ thermodynamic slab ocean that calculates ocean heat transport through linear diffusion based on the local temperature gradient and a latitude-dependent diffusion coefficient (Thompson and Pollard, 1995). This method of heat transport works well for paleoclimate simulations because a flux correction is not prescribed as in many other slab ocean models. The model also includes a dynamic-thermodynamic sea-ice model with six layers. Previous studies show the slab ocean can fairly accurately replicate the modern climate (Thompson and Pollard, 1997) and the GENESIS GCM has been used extensively for paleoclimate simulations (e.g., DeConto and Pollard, 2003; Horton et al., 2007). We expect our model correctly captures the short-term ocean response to orbital changes, but we cannot address the longer-term changes such as those from the thermohaline circulation. Orbital sensitivity experiments using a dynamic ocean have found seaice results that are in agreement with the slab ocean response (Tuenter et al., 2005). Furthermore, dynamic ocean studies suggest that the fast acting sea-ice response controls the changes in the thermohaline circulation (e.g., Tuenter et al., 2004; Poulsen and Zhou, 2013). Nevertheless, additional transient orbital studies using a dynamic ocean model are needed to assess the full impact of the ocean on the ice response.

While we demonstrate the significance of surface feedbacks on climate response, we are unable to quantify the relative significance of the ocean, sea-ice, and vegetation feedbacks due to the large computational expense of a complete feedback analysis. To isolate the effects of the differences in vegetation response, we switch the equilibrium vegetation outputs of obliquity and precession for the climate-only experiments, and then rerun the snapshots to new equilibriums. We find that swapping vegetation decreases the temperature sensitivity difference to insolation forcing between obliquity and precession from 1.73 to 1.60 times. More significantly, the maximum high-latitude summer temperature response decreased by $0.35^{\circ} \mathrm{C}$ to obliquity and increased by $0.85^{\circ} \mathrm{C}$ to precession. The temperature responses are as expected; lower surface albedo, caused by a transition from tundra to boreal forest, allows great surface warming. Unfortunately, the same technique cannot be used to explore the ocean and sea-ice feedbacks because swapping ocean temperatures and sea-ice coverage compromises the energy balance of the system.

As previously mentioned, other studies find surface feedbacks to be important climate response modifiers. 
For example, Horton and Poulsen (2009) report the vegetation feedback is critical for ice-sheet retreat in the Paleozoic Era. Furthermore, Claussen (2009) observed sea ice and vegetation to be important for surface temperature with synergy between the feedbacks amplifying both responses. Recently, Erb et al. (2013) used the radiative kernel method to deconstruct the feedback responses in several orbital snapshot experiments. However, their study did not look at the feedbacks associated with vegetation and land ice. We plan to perform a feedback analysis of "slow" climate responses in the future. Despite these limitations, our study is the first to examine the role of obliquity and precession using transient orbits with a complex Earth system model that includes dynamic land ice.

\section{Supplementary material related to this article is available online at http://www.clim-past.net/10/41/2014/ cp-10-41-2014-supplement.pdf.}

Acknowledgements. We thank the Climate Change Research Lab at the University of Michigan for their discussion and suggestions. We are grateful to Kerim Nisancioglu and two anonymous reviews, Roland Zech, and editor Marie-France Loutre whose comments greatly improved this manuscript. This research was funded by NSF-OCE-0902258.

Edited by: M.-F. Loutre

\section{References}

Abe-Ouchi, A., Segawa, T., and Saito, F.: Climatic Conditions for modelling the Northern Hemisphere ice sheets throughout the ice age cycle, Clim. Past, 3, 423-438, doi:10.5194/cp-3-423-2007, 2007.

Bender, M. L.: Orbital tuning chronology for the Vostok climate record supported by trapped gas composition, Earth Planet. Sc. Lett., 204, 275-289, doi:10.1016/S0012-821X(02)00980-9, 2002.

Berger, A. and Loutre, M. F.: Insolation values for the climate of the last 10 million years, Quaternary Sci. Rev., 10, 297-317, doi:10.1016/0277-3791(91)90033-Q, 1991.

Birchfield, G. E., Weertman, J., and Lunde, A. T.: A paleoclimate model of northern hemispheric ice sheets, Quaternary Res., 15, 126-42, doi:10.1016/0033-5894(81)90100-9, 1981.

Clark, P. U. and Pollard, D.: Origin of the middle Pleistocene transition by ice sheet erosion of regolith, Paleoceanography, 13, 1-9, doi:10.1029/97PA02660, 1998.

Claussen, M.: Late Quaternary vegetation-climate feedbacks, Clim. Past, 5, 203-216, doi:10.5194/cp-5-203-2009, 2009.

Claussen, M., Fohlmeister, J., Ganopolski, A., and Brovkin, V.: Vegetation dynamics amplifies precessional forcing, Geophys. Res. Lett., 33, L09709, doi:10.1029/2006GL026111, 2006.

Cortijo, E., Lehman, S., Keigwin, L., Chapman, M., Paillard, D., and Labeyrie, L.: Changes in Meridional Temperature and Salinity Gradients in the North Atlantic Ocean $\left(30^{\circ}-72^{\circ} \mathrm{N}\right)$ during the Last Interglacial Period, Paleoceanography, 14, 23-33, doi:10.1029/1998PA900004, 1999.
Crucifix, M. and Loutre, M. F.: Transient simulations over the last interglacial period (126-115 kyr BP): feedback and forcing analysis, Clim. Dynam., 19, 419-433, doi:10.1007/s00382-0020234-z, 2002.

DeConto, R. M. and Pollard, D.: A coupled climate-ice sheet modeling approach to the Early Cenozoic history of the Antarctic ice sheet, Palaeogeogr. Palaeocl., 198, 39-52, doi:10.1016/S00310182(03)00393-6, 2003.

Erb, M. P., Broccoli, A. J., and Clement, A. C.: The contribution of radiative feedbacks to orbitally-driven climate change, J. Climate, 26, 5897-5914, doi:10.1175/JCLI-D-12-00419.1, 2013.

Gallimore, R. G. and Kutzbach, J. E.: Snow cover and sea ice sensitivity to generic changes in Earth orbital parameters, J. Geophys. Res., 100, 1103-1120, doi:10.1029/94JD02686, 1995.

Gallimore, R. G. and Kutzbach, J. E.: Role of orbitally induced changes in tundra area in the onset of glaciation, Nature, 381, 503-505, doi:10.1038/381503a0, 1996.

González-Sampériz, P., Leroy, S. A., Carrión, J. S., Fernández, S., García-Antón, M., Gil-García, M. J., Uzquiano, P., Valero-Garcés, B., and Figueiral, I.: Steppes, savannahs, forests and phytodiversity reservoirs during the Pleistocene in the Iberian Peninsula, Rev. Palaeobot. Palyno., 162, 427-457, doi:10.1016/j.revpalbo.2010.03.009, 2010.

Hays, J. D., Imbrie, J., and Shackleton, N. J.: Variations in the Earth's orbit: pacemaker of the ice age, Science, 194, 1121-1132, doi:10.1126/science.194.4270.1121, 1976.

Herrington, A. R. and Poulsen, C. J.: Terminating the last Interglacial: the role of ice sheet- climate feedbacks in a GCM asynchronously coupled to an ice sheet model, J. Climate, 25, 18711882, doi:10.1175/JCLI-D-11-00218.1, 2011.

Horton, D. E. and Poulsen, C. J.: Orbital and CO2 forcing of late Paleozoic continental ice sheets, Geophys. Res. Lett., 34, L19708, doi:10.1029/2007GL031188, 2007.

Horton, D. E. and Poulsen, C. J.: Paradox of late Paleozoic glacioeustasy, Geology, 37, 715-718, doi:10.1130/G30016A.1, 2009.

Horton, D. E., Poulsen, C. J., and Pollard, D.: Influence of highlatitude vegetation feedbacks on late Palaeozoic glacial cycles, Nat. Geosci., 3, 572-577, doi:10.1038/ngeo922, 2010.

Huybers, P.: Early Pleistocene Glacial cycles and the integrated summer insolation forcing, Science, 313, 508-511, doi:10.1126/science.1125249, 2006.

Huybers, P.: Combined obliquity and precession pacing of late Pleistocene deglaciations, Nature, 480, 229-232, doi:10.1038/nature10626, 2011.

Jackson, C. S. and Broccoli, A. J.: Orbital forcing of Arctic climate: mechanisms of climate response and implications for continental glaciation, Clim. Dynam., 21, 539-557, doi:10.1007/s00382003-0351-3, 2003.

Kaplan, J. O., Bigelow, N. H., Prentice, I. C., Harrison, S. P., Bartlein, P. J., Christensen, T. R., Cramer, W., Matveyeva, N. V., McGuire, A. D., Murray, D. F., Razzhivin, V. Y., Smith, B., Walker, D. A., Anderson, P. M., Andreev, A. A., Brubaker, L. B., Edwards, M. E., and Lozhkin, A. V.: Climate change and Arctic ecosystems: 2. modeling, paleodata-model comparisons, and future projections, J. Geophys. Res., 108, 8171-8188, doi:10.1029/2002JD002559, 2003.

Koenig, S. J., DeConto, R. M., and Pollard, D.: Late Pliocene to Pleistocene sensitivity of the Greenland Ice Sheet in response 
to external forcing and internal feedbacks, Clim. Dynam., 37, 1247-1268, doi:10.1007/s00382-011-1050-0, 2011.

Lee, S.-Y. and Poulsen, C. J.: Amplification of obliquity forcing through mean annual and seasonal atmospheric feedbacks, Clim. Past, 4, 205-213, doi:10.5194/cp-4-205-2008, 2008.

Lee, S.-Y. and Poulsen, C. J.: Obliquity and precessional forcing of continental snow fall and melt: implications for orbital forcing of Pleistocene ice ages, Quaternary Sci. Rev., 28, 2663- 2674, doi:10.1016/j.quascirev.2009.06.002, 2009.

Lisiecki, L. E. and Raymo, M. E.: A Pliocene-Pleistocene stack of 57 globally distributed benthic $\delta 180$ records, Paleoceanography, 20, PA1003, doi:10.1029/2004PA001071, 2005.

Lisiecki, L. E. and Raymo, M. E.: Plio-Pleistocene climate evolution: trends and transitions in glacial cycle dynamics, Quaternary Sci. Rev., 26, 56-69, doi:10.1016/j.quascirev.2006.09.005, 2007.

Marshall, S. J. and Clarke, G. K. C.: Modeling North American freshwater runoff through the Last Glacial Cycle, Quaternary Res., 52, 300-315, doi:10.1006/qres.1999.2079, 1999.

Petit, J. R., Jouzel, J., Raynaud, D., Barkov, N. I., Barnola, J. M., Basile, I., Bender, M., Chappellaz, J., Davis, M., and Delaygue, G.: Climate and atmospheric history of the past $420000 \mathrm{yr}$ from the Vostok ice core, Antarctica, Nature, 399, 429-436, doi:10.1038/20859, 1999.

Pollard, D. and DeConto, R. M.: Description of a hybrid ice sheetshelf model, and application to Antarctica, Geosci. Model Dev. Discuss., 5, 1077-1134, doi:10.5194/gmdd-5-1077-2012, 2012.

Pollard, D. and Reusch, D. B.: A calendar conversion method for monthly mean paleoclimate model output with orbital forcing, J. Geophys. Res., 107, 4615-4622, doi:10.1029/2002JD002126, 2002.

Poulsen, C. J. and Zhou, J.: Sensitivity of Arctic Climate Variability to Mean State: Insights from the Cretaceous, J. Climate, 26, 7003-7022, doi:10.1175/JCLI-D-12-00825.1, 2013.
Raymo, M. E. and Nisancioglu, K.: The $41 \mathrm{kyr}$ world: Milankovitch's other unsolved mystery, Paleoceanography, 18, 1011-1017, doi:10.1029/2002PA000791, 2003.

Raymo, M. E., Lisiecki, L. E., and Nisancioglu, K. H.: PlioPleistocene ice volume, Antarctic climate, and the global $\delta 180$ record, Science, 313, 492-495, doi:10.1126/science.1123296, 2006.

Robinson, A., Calov, R., and Ganopolski, A.: An efficient regional energy-moisture balance model for simulation of the Greenland Ice Sheet response to climate change, The Cryosphere, 4, 129144, doi:10.5194/tc-4-129-2010, 2010.

Sosdian, S. and Rosenthal, Y.: Deep-sea temperature and ice volume changes across the Pliocene-Pleistocene climate transitions, Science, 325, 306-310, doi:10.1126/science.1169938, 2009.

Thompson, S. L. and Pollard, D.: A Global Climate Model (GENESIS) with a Land-Surface Transfer Scheme (LSX). Part I: Present Climate Simulation, J. Climate, 8, 732-761, doi:10.1175/15200442(1995)008<0732:AGCMWA>2.0.CO;2, 1995.

Thompson, S. L. and Pollard, D.: Greenland and Antarctic mass balances for present and doubled atmospheric $\mathrm{CO}_{2}$ from the GENESIS version-2 global climate model, J. Climate, 10, 871-900, doi:10.1175/1520-0442(1997)010à0871:GAAMBF_2.0.CO;2, 1997.

Tuenter, E., Weber, S. L., and Hilgen, F. J.: Sea-ice feedbacks on the climatic response to precession and obliquity forcing, Geophys. Res. Lett., 32, L24704, doi:10.1029/2005GL024122, 2005.

van den Berg, J., van de Wal, R., and Oerlemans, H.: A mass balance model for Eurasian Ice Sheet for the last 120,000 years, Global Planet. Change, 61, 194-208, doi:10.1016/j.gloplacha.2007.08.015, 2008. 